\title{
The CURB-65 scoring system in severity assessment of Eastern Nigerian patients with community-acquired pneumonia: a prospective observational study
}

\author{
*Godwin C Mbata', Chinwe J Chukwuka², Cajetan C Onyedum², Basden J C Onwubere ${ }^{2}$ \\ 1 Department of Medicine, Federal Medical Centre, Owerri, Nigeria \\ 2 Department of Medicine, University of Nigeria Teaching Hospital Enugu (UNTH), Enugu, Nigeria
}

Originally received 17th M ay 2012; revised 20th June 2012; further revision 28th June 2012; resubmitted 21st November; final revision 21st December 2012; accepted 2nd January 2013; online 1st May 2013

\begin{abstract}
Background: Community-acquired pneumonia (CAP) is a major cause of morbidity and mortality in Nigeria. Severity assessment is a major starting point in the proper management of CAP. The BTS guideline for managing this condition is simple and does not require sophisticated equipment. Adherence to this guideline will improve CAP management in Nigeria.

Aims: To assess the usefulness of the CURB-65 score in the management of CAP patients in Nigeria and to determine the outcome in relation to the degree of severity using CURB-65.

Methods: A prospective observational study of 80 patients with CAP was carried out in the University of Nigeria Teaching Hospital Enugu, Nigeria from December 2008 to June 2009. The patients were classified into three risk groups and the ability of the CURB-65 score to predict the 30-day mortality rate and the need for ICU admission was determined.

Results: Eighty patients were recruited, 39 of whom were men, giving a male to female ratio of 1:1.05. The mean age was $56 \pm 18$ years. Thirty-seven patients (46.3\%) were outpatients, 13 with CURB score 0, 21 with CURB score 1, two with CURB score 2, and one with CURB score 3. Of the 43 patients (53.7\%) admitted to hospital, six, 13, 14, and 10 had scores of 4, 3, 2, and 1, respectively. The ICU admission rate was $10 \%$. Twelve patients died, $2.2 \%$ in the low-risk group, $12.5 \%$ in the intermediate-risk group, and $45 \%$ in the high-risk group. Conclusions: The CURB-65 score is a simple method of assessing and risk stratifying CAP patients. It is particularly useful in a busy emergency department because of its ability to identify a reasonable proportion of low-risk patients for potential outpatient care.

(C) 2013 Primary Care Respiratory Society UK. All rights reserved.

GC Mbata et al. Prim Care Respir J 2013; 22(2): 175-180

http://dx.doi.org/10.4104/pcrj.2013.00034
\end{abstract}

Keywords community-acquired pneumonia, CURB-65, Eastern Nigeria, ICU admissions, mortality, severity assessment

\section{Introduction}

Community-acquired pneumonia (CAP) is commonly defined as an acute infection of the pulmonary parenchyma that is associated with symptoms and signs of acute infection accompanied by the presence of an acute infiltrate on the chest $x$-ray in a patient who has not resided in a hospital or healthcare facility in the previous 14 days. ${ }^{1}$ The overall rate of pneumonia is about 8-15 per 1000 per year, with the highest rates at extremes of age. ${ }^{2}$

CAP is common in both developed and developing nations. The incidence rates in most developing nations are not known. There is little documentation on CAP in Nigeria, but earlier work done more than three decades ago estimated that about $20 \%$ of Nigerians with pneumonia will die. ${ }^{3}$ The cost of treating a patient with CAP could be as little as 150-350 US dollars as an outpatient and as high as 7,500 US dollars as an inpatient. ${ }^{4}$ Mortality averages more than $14 \%$, but is less than $1 \%$ in those who do not require hospital admission. ${ }^{1,5,6}$ There is therefore a need to stratify patients according to severity and to identify which patients can be managed as outpatients, inpatients, or in the intensive care unit (ICU).

The care of patients with CAP involves a series of interrelated steps, so it is not surprising that great variability in care exists. ${ }^{7.8}$ Due to this variability, different methods of assessment have evolved over a period of time. These include the Pneumonia Severity Index adopted by the American Thoracic Society and widely used in North America. ${ }^{9}$ It is a two-step scoring system using 20 variables and was developed to identify low-risk patients or potential candidates for

\footnotetext{
* Corresponding author: Dr Godwin C Mbata, Department of Medicine, Federal Medical Centre,PMB 1010, Owerri, Nigeria.

Tel: +234-803-3569-235 E-mail: mbatag@yahoo.com.
} 
outpatient care. The CURB score (Confusion, Urea, Respiratory rate, Blood pressure) is a modified version of the British Thoracic Society (BTS) tool which relies on four parameters for scoring. ${ }^{10,11}$ In 2003, Lim et al. 10,11 added age $\geq 65$ years as a fifth prognostic variable to the CURB scoring system and turned it into a 6-point scoring scale (0-5) known as CURB-65, which was adopted by the BTS as a new severity assessment strategy for CAP in 2004. The CURB-65 score is now widely used and has been independently validated in over 11,000 patients in nine countries..$^{10}$ There is a need to apply this rule to patients with CAP in Nigeria to investigate its efficiency in the management of CAP patients in our own environment.

The aim of this study was to assess the usefulness of the validated prediction rule CURB-65 score in the management of CAP patients in Nigeria and to determine the outcome in relation to the degree of severity using this scoring system.

\section{Methods}

\section{Study design and patients}

Data were collected prospectively from consecutively recruited patients seen at the accident and emergency and medical outpatients. Investigations were performed in accident and emergency or during the time of admission for admitted patients. All patients with a clinical and radiological diagnosis of CAP from December 2008 to June 2009 were recruited for the study. Ethical approval was obtained from the ethics committee of the hospital.

\section{Setting}

The study was performed at the University of Nigeria Teaching Hospital Enugu, Nigeria, a tertiary health institution with 700 bed spaces which serves Enugu and most of south-eastern Nigeria. The hospital serves a population of over 1.5 million people and sees over 6,000 patients annually. About $2.02 \%$ of these patients are treated for CAP annually. ${ }^{12}$

\section{Definitions}

CAP was defined as an acute infection of the pulmonary parenchyma associated with symptoms and signs of acute infection, followed by the presence of an acute infiltrate on the chest $\mathrm{x}$-ray in a patient who was not resident in a hospital or healthcare facility in the previous 14 days. ' All the patients were assessed by a specialist physician before admission and by a pulmonologist before discharge. Patients with CAP were classified into low-, intermediate-, and high-risk groups according to CURB-65 scoring systems. The 30-day all-cause mortality and the need for ICU admission were documented in each risk group.

\section{Inclusion and exclusion criteria}

All consenting adults aged $>18$ years were included. Patients were also included if they have two or more symptoms and infiltrates on the chest $x$-ray. ${ }^{13}$ Exclusion criteria included patients admitted to the hospital in the previous 14 days, those whose symptoms developed 48 hrs after admission, ${ }^{13}$ patients with tuberculosis or a previous chest $x$-ray which may conflict with a diagnosis of CAP, and patients who were unwilling to participate.

\section{Radiological evaluation}

The chest $\mathrm{x}$-ray was reported by a consultant radiologist. The same radiologist was used for all the reports throughout the period of the study. The machine used was a Siemens si-400, model Gm 0388b2.

\section{Data collection}

A standard questionnaire designed to cover personal data and review symptoms of CAP was used for the study. Data collected during subject assessment included age, gender, and co-morbidity (coexisting illness). Documented physical signs included pulse, axillary temperature, respiratory rate, and blood pressure. Blood pressure was done prior to fluid resuscitation or inotropic support. ${ }^{14}$ Confusion was assessed in this study as a new disorientation in time, place, or person. Specimens for full blood count, erythrocyte sedimentation rate, electrolytes, and urea were collected promptly and sent to the laboratory and results were obtained and recorded. HIV testing and counselling was done in 35 subjects (43.7\%). Sputum was collected in sterile screw containers. Adequacy of sputum was defined as $>2 \mathrm{ml}$ sputum containing $<15$ epithelial cells on microscopy. ${ }^{15}$

After the patients had been assessed and samples collected, they were assessed for mortality risk using the BTS CURB-65 score as follows:

$\mathrm{C}=$ confusion (defined as new disorientation in time,

place or person) $=1$.

$U=$ serum urea $\geq 7.0 \mathrm{mmol} / \mathrm{L}=1$.

$\mathrm{R}=$ respiratory rate $\geq 30$ cycles $/ \mathrm{min}=1$.

$\mathrm{B}=$ systolic $\mathrm{BP}<90$ or diastolic $\mathrm{BP} \leq 60=1$.

$65=$ age $\geq 65$ years $=1$

Each subject scored a minimum of score of 0 and a maximum of 5. Scores of $0-1,2$, and 3--5 were classed as low-risk, intermediate-risk, and high-risk for mortality associated with CAP, respectively. The patients were then placed on antibiotics using the BTS care guidelines. ${ }^{11,16}$ Patients who were managed at home were observed in casualty for the first 48 hrs and their antibiotics were reviewed with the sputum culture result. The serum urea result was also collected and used to complete the CURB-65 score. If the patient was managed at home, he/she was followed up in the outpatient clinic, then reviewed weekly for 30 days and the outcome documented. If the patient was admitted, he/she was monitored in the ward and transferred to ICU when the need arose. Factors which predicted ICU transfer included a high CURB-65 score, cyanosis, hypothermia or fever not subsiding with treatment, and persistent hypotension. When discharged, the patient was followed up in the outpatient clinic weekly and the outcome documented. During the follow-up visits, patients were reexamined and vital signs were cross-checked. Investigations such as serum urea, chest x-ray, sputum culture, and full blood count were repeated for patients who were not doing well and their treatment adjusted accordingly.

\section{Data analysis}

The data were analysed with Epi-info Version 3.4. Data were presented in tables and charts. Sample mean, standard deviation and the chi-square test were used for statistical significance. Severity was assessed using the CURB-65 scoring system. The primary interest was the number of admissions and outpatients depending on the CURB65 score. Outcomes of interest were 30-day mortality and the need for ICU admission. Event rates were based on the first episode of CAP and did not include multiple events per person. In all, p values of 0.05 were regarded as significant and conclusions were drawn based on this level of significance. Confidence intervals were set at 95\%. 


\begin{tabular}{|c|c|c|c|}
\hline $\begin{array}{l}\text { CURB-65 } \\
\text { risk group }\end{array}$ & $\begin{array}{l}\text { Outpatients } \\
(\mathrm{N}=37)\end{array}$ & $\begin{array}{l}\text { Inpatients } \\
(\mathrm{N}=43)\end{array}$ & $\begin{array}{l}\text { Total } \\
(\mathrm{N}=80)\end{array}$ \\
\hline 0 & $13(100 \%)$ & $0(0 \%)$ & $13(16.3 \%)$ \\
\hline 1 & $21(67.7 \%)$ & $10(32.3 \%)$ & $31(38.7 \%)$ \\
\hline 2 & $2(12.5 \%)$ & $14(87.5 \%)$ & $16(20.0 \%)$ \\
\hline 3 & $1(7.1 \%)$ & $13(92.9 \%)$ & $14(17.5 \%)$ \\
\hline 4 & $0(0 \%)$ & $6(100 \%)$ & $6(7.5 \%)$ \\
\hline 5 & $0(0 \%)$ & $0(0 \%)$ & $0(0 \%)$ \\
\hline \multicolumn{4}{|c|}{$\mathrm{X}^{2}$ for linear trend $=36.539, \mathrm{p}=0.000$ (significant) } \\
\hline \multicolumn{4}{|c|}{ All data are numbers (\%) unless otherwise stated. } \\
\hline \multicolumn{4}{|c|}{$\begin{array}{l}\text { The percentages in the first two columns relate to the proportion of subjects } \\
\text { who are either inpatients or outpatients. The percentages in the last column } \\
\text { relate to the proportion of subjects within the different CURB- } 65 \text { categories. }\end{array}$} \\
\hline
\end{tabular}

\section{Results}

Eighty-eight patients were assessed during the study. Eight patients were excluded based on chest $x$-ray findings and history of treatment with anti-tuberculous drugs, so 80 patients were finally recruited (39 men and 41 women), giving a male to female ratio of $1: 1.05$. The mean age was $56 \pm 18$ years.

\section{Inpatients, outpatients, and ICU admissions}

As the CURB-65 score increased there was a significant increase in the proportion of cases admitted; 44 patients (55\%) were low-risk (CURB-65 score 0-1), 16 (20\%) were intermediate-risk (CURB-65 score 2), and 20 (25\%) were high-risk patients (CURB-65 score 3-5) (Table 1).

As the CURB-65 score increased there was a significant increase in the proportion of cases that were severe enough to be admitted to the ICU. When patients were classified according to low-,

\section{Table 2. ICU admission in each CURB-65 risk class}

\begin{tabular}{|c|c|c|}
\hline CURB-65 score & $\begin{array}{l}\text { Total admitted } \\
(\mathrm{N}=43)\end{array}$ & $\begin{array}{l}\text { Admitted to ICU } \\
(\mathrm{N}=8)\end{array}$ \\
\hline 0 & $0(0 \%)$ & $0(0 \%)$ \\
\hline 1 & $10(23.3 \%)$ & $0(0 \%)$ \\
\hline 2 & $14(32.6 \%)$ & $2(14.3 \%)$ \\
\hline 3 & $13(30.2 \%)$ & $3(23.1 \%)$ \\
\hline 4 & $6(13.9 \%)$ & $3(50.0 \%)$ \\
\hline 5 & $0(0 \%)$ & $0(0 \%)$ \\
\hline \multicolumn{3}{|c|}{$\mathrm{X}^{2}$ for linear trend=5.778; $\mathrm{p}=0.01623$ (significant) } \\
\hline \multicolumn{3}{|c|}{$\begin{array}{l}\text { Risk stratification using CURB- } 65 \text { rule (outcome in terms } \\
\text { of ICU admissions) }\end{array}$} \\
\hline Low (score 0-1) & $10(23.3 \%)$ & $0(0 \%)$ \\
\hline Intermediate (score 2) & $14(32.6 \%)$ & $2(14.3 \%)$ \\
\hline High (score 3-5) & $19(44.1 \%)$ & $6(31.6 \%)$ \\
\hline \multicolumn{3}{|c|}{$X^{2}=4.57 ; p=0.102$ (not significant) } \\
\hline \multicolumn{3}{|c|}{ All data are numbers (\%) unless otherwise stated. } \\
\hline \multicolumn{3}{|c|}{$\begin{array}{l}\text { The percentages in the } 2 \text { nd column relate to the proportion of patients admitted } \\
\text { within each CURB65 score, the percentages in the last column relate to ICU } \\
\text { admissions within the different CURB65 categories. }\end{array}$} \\
\hline
\end{tabular}

Table 3. Thirty-day mortality in each CURB-65 risk class

\begin{tabular}{|c|c|c|}
\hline CURB-65 score & $\begin{array}{l}\text { Total patients } \\
(\mathrm{N}=80)\end{array}$ & $\begin{array}{l}\text { 30-day mortality } \\
(\mathrm{N}=12)\end{array}$ \\
\hline 0 & $13(16.3 \%)$ & $0(0 \%)$ \\
\hline 1 & $31(38.7 \%)$ & $1(3.3 \%)$ \\
\hline 2 & $16(20.0 \%)$ & $2(12.5 \%)$ \\
\hline 3 & $14(17.5 \%)$ & $5(35.7 \%)$ \\
\hline 4 & $6(7.5 \%)$ & $4(66.7 \%)$ \\
\hline 5 & $0(0 \%)$ & $0(0 \%)$ \\
\hline \multicolumn{3}{|c|}{$X^{2}$ for linear trend $=19.701 ; p=0.000$ (significant) } \\
\hline \multicolumn{3}{|c|}{$\begin{array}{l}\text { Risk stratification using CURB-65 rule (outcome in terms of } \\
\text { 30-day mortality) }\end{array}$} \\
\hline Low (score 0-1) & $44(55 \%)$ & $1(2.2 \%)$ \\
\hline Intermediate (score 2) & $16(20 \%)$ & $2(12.5 \%)$ \\
\hline High (score 3-5) & $20(25 \%)$ & $9(45 \%)$ \\
\hline \multicolumn{3}{|c|}{$X^{2}=19.79 ; p=0.0000$ (significant) } \\
\hline \multicolumn{3}{|c|}{ All data are numbers (\%) unless otherwise stated. } \\
\hline \multicolumn{3}{|c|}{$\begin{array}{l}\text { The percentages in the 2nd column relate to the proportion of patients within } \\
\text { each CURB65 Score. The percentages in the last column relate to the } 30 \text {-day } \\
\text { mortality within the different CURB65 categories. }\end{array}$} \\
\hline
\end{tabular}

intermediate, and high-risk, no low-risk patient was treated in the ICU but many of the high-risk patients were treated in the ICU (Table 2).

\section{Thirty-day mortality}

Table 3 shows the distribution of patients and 30-day mortality outcome in each class of the CURB-65 rule. There was a significant increase in the proportion of deaths as the CURB-65 score increased. When the patients were classified into low-, intermediate-, and highrisk classes, the findings show that death was significantly higher in the high-risk group (Table 3).

\section{Age distribution and mortality}

Mortality was noted to be highest in those aged $\geq 65$ years and lowest in the younger age groups with patients aged 35-44 and those aged $\leq 34$ years each recording $8.3 \%$. When the age-specific case fatality rate was calculated, it was still highest in those aged $\geq 65$ years (18.5\%).

\begin{tabular}{l} 
Table 4 a. Contribution of different co-morbidities to \\
mortality outcome \\
\begin{tabular}{ll} 
Co-morbidities, $n(\%)$ & Mortality \\
\hline Congestive cardiac failure, $n=10(21.3 \%)$ & 3 \\
\hline COPD, $n=6(12.8 \%)$ & 2 \\
\hline Malignancies, $n=6(12.8 \%)$ & 1 \\
\hline Other lung diseases, $n=5(10.6 \%)$ & 1 \\
\hline HIV infection, $n=5(10.6 \%)$ & 2 \\
\hline Cerebrovascular disease, $n=5(10.6 \%)$ & 1 \\
\hline Chronic kidney disease, $n=4(8.5 \%)$ & 0 \\
\hline Diabetes mellitus, $n=4(8.5 \%)$ & 0 \\
\hline Chronic liver disease, $n=2(4.3 \%)$ & 1 \\
\hline Total=47 (100\%) & $11(23.4 \%)$ \\
\hline CoPD=chronic obstructive pulmonary disease.
\end{tabular} \\
\hline
\end{tabular}


Table 4b. Cross-tabulation of co-morbidity and mortality in patients with community-acquired pneumonia

\begin{tabular}{ll} 
Co-morbidity & No co-morbidity \\
\hline Mortality absent, $n=36(76.6 \%)$ & Mortality absent, $n=32(97.0 \%)$ \\
\hline Mortality present, $n=11(23.4 \%)$ & Mortality present, $n=1(3.0 \%)$ \\
\hline Total, $n=47(100 \%)$ & Total, $n=33(100 \%)$ \\
\hline$X^{2}=6.31, p=0.012$ (significant). Odds ratio $=9.78$.
\end{tabular}

\section{Contribution of co-morbidity to mortality outcome}

Forty-seven of the 80 patients had co-morbidities. The 30-day mortality rate for those with co-morbidities was $23.4 \%$ compared with only $3 \%$ in those with no co-morbidities (Table $4 a$ ). A crosstabulation of co-morbidity and mortality is shown in Table 4b.

Using the Charlson Co-morbidity Index, the overall co-morbidity score was high (3) for chronic kidney disease and chronic liver disease with 1-year estimated mortality rates of $52 \%$ and $56 \%$, respectively. For other conditions, the overall co-morbidity score was moderate (2) with 1-year estimated mortality rates of $26 \%$ each (Table 4c).

Thirty-five patients (43.8\%) were screened for HIV, five of whom (14.3\%) were positive.

Specificity, sensitivity, positive and negative predictive values of 30-day mortality of CURB-65 rule

Table 5 shows that sensitivity was high with a low CURB-65 score and decreased as the score increased, while specificity increased with increasing CURB-65 score. The CURB-65 score has high negative and low positive predictive values.

\section{Disaussion}

\section{Main findings}

This study assessed the severity and outcome of CAP using the CURB65 score and found it to be a convenient tool for assessing CAP patients in Nigeria.

Our study had an equal male to female ratio of 1:1.05 with a slight female preponderance and many of our patients were aged $\geq 65$ years (33.75\%).
Table 5. Sensitivity, specificity, positive and negative predictive values of 30-day mortality of CURB-65 rule

\begin{tabular}{lllll} 
CURB-65 score & Sensitivity & Specificity & PPV & NPV \\
\hline 0 & 100.0 & 93.2 & 15.0 & 85.0 \\
\hline 1 & 92.3 & 94.4 & 14.8 & 84.0 \\
\hline 2 & 85.7 & 95.8 & 14.6 & 82.0 \\
\hline 3 & 80.0 & 97.1 & 14.5 & 81.9 \\
\hline 4 & 75.0 & 98.6 & 14.3 & 81.0 \\
\hline 5 & 70.6 & 100.0 & 14.1 & 80.0 \\
\hline PPV=positive predictive value, NPV=negative predictive value.
\end{tabular}

The study revealed that the majority of our patients with a low-risk score were managed at home with a good outcome while most of the intermediate- and high-risk patients were admitted. As in other studies, ICU admission increased with increasing risk score. This study found an ICU admission of $10 \%$ of the total number of patients.

The overall outcome showed a mortality rate of 15\% (12 patients) and the 30-day mortality increased as the CURB-65 score increased. The mortality rate was higher among elderly subjects aged $\geq 65$ years and also higher in subjects with co-morbidities. A comparison of mortality in patients with and without co-morbidities showed a significant difference $(\mathrm{p}=0.012)$.

The findings in this study showed that CURB-65 has high negative and low positive predictive values at all cut-off points. The sensitivity was high at a low CURB-65 score and specificity was high at a high CURB-65 score.

\section{Strengths and limitations of the study}

The strength of this study lies in its prospective design, wide age range, use of the BTS guidelines for the management of patients, and the novelty of this study in the West African sub-region.

All $x$-rays were reported by the same radiologist, giving rise to less potential bias in radiological interpretation.

This was a prospective observational short-term study and could not look at the long-term effects of the disease on the patients. A larger sample size is required to support some of the conclusions made in this study.

Table 4c. Applying the Charleson Co-morbidity Index to estimate the effect of the diseases on CAP outcome

\begin{tabular}{|c|c|c|c|}
\hline Co-morbidity present & & Charlson Co-mork & $(\mathrm{CCl})$ \\
\hline Diseases, $\mathrm{n}(\%)$ & Mortality & Overall CCI score & 1 year estimated mortality rate $(\%)$ \\
\hline Congestive cardiac failure, $n=10(21.3 \%)$ & 3 & 2 (moderate) & 26 \\
\hline COPD, $n=6(12.8 \%)$ & 2 & 2 (moderate) & 26 \\
\hline Malignancies, $n=6(12.8 \%)$ & 1 & 2 (moderate) & 26 \\
\hline Other lung diseases, $n=5(10.6 \%)$ & 1 & 2 (moderate) & 26 \\
\hline HIV infection, $n=5(10.6 \%)$ & 2 & 2 (moderate) & 26 \\
\hline Cerebrovascular disease, $n=5(10.6 \%)$ & 1 & 2 (moderate) & 26 \\
\hline Chronic kidney disease, $n=4(8.5 \%)$ & 0 & 3 (high) & 52 \\
\hline Diabetes mellitus, $n=4(8.5 \%)$ & 0 & 2 (moderate) & 26 \\
\hline Chronic liver disease, $n=2(4.3 \%)$ & 1 & 3 (high) & 56 \\
\hline Total, $n=47(100 \%)$ & $11(23.4 \%)$ & & \\
\hline
\end{tabular}




\section{Interpretation of findings in relation to previously published work}

The study had an almost equal male to female ratio of 1:1.05. This is in agreement with most other studies which found equal sex ratios or slight male or female preponderance. ${ }^{3,17,18}$

The CURB-65 score remains a standard scoring system for identifying patients who can be managed at home. This is in agreement with studies carried out by two different investigators which showed that the CURB-65 rule is suitable for use in the emergency department because of the simplicity of its application and the ability to identify low-risk patients. ${ }^{10,19}$ Capelastegui et al. ${ }^{20}$ in a similar study, confirmed that CURB-65 and the simpler CRB-65 are simple clinical approaches that can be applied in the community setting to augment clinical judgement regarding the need for hospital admission.

The rate of admission to the ICU in this study was $10 \%$. This compares with admission rates of $4 \%, 10 \%$, and $16.7 \%$ in other studies. ${ }^{10,21,22}$ The reason for the variation is that the criteria for ICU admission differ from hospital to hospital and from one country to another, and disease severity is not the only factor to consider. Other factors such as disease prognosis, pre-morbid status, patient age, and availability of ICU resources are all routinely considered by intensive care physicians before admitting patients to the ICU. 10,23,24 This implies that this prediction rule is not very useful in predicting ICU admission, although it gives an indication of disease severity.

The 30-day mortality increased as the CURB-65 score increased, and this is comparable to a previous study reported from Spain. ${ }^{19}$ This shows that the CURB-65 rule is a good tool for severity assessment in our CAP patients. When the patients were risk-stratified, $2 \%$ of the low-risk group died compared with $12.5 \%$ of the intermediate-risk group and $45 \%$ of the high-risk group. This is in agreement with a study by Ewig et al. ${ }^{22}$ which showed that $20-50 \%$ of high-risk patients would die from CAP.

Age and co-morbidities are known to influence the outcome of CAP. This supports many of the findings in other countries, ${ }^{-1,17,25}$ for example, studies at the University of Pittsburgh, USA, showed that the incidence rate of CAP rose five-fold and mortality doubled as age increased from 65-69 years to $>90$ years ${ }^{25}$ and, in the Spanish Evan-65 study, the burden of CAP was found to increase with age. ${ }^{26}$ All these give credence to the findings in this study.

Heart failure, chronic obstructive pulmonary disease (COPD), and malignancies were the leading co-morbidities found in this study, which agrees with the reports of several other studies. ${ }^{1,22,27}$ Cough is a frequent symptom of heart failure, so exposure to microbial agents may result in CAP. Studies have shown an increased rate of lower respiratory tract infections in patients with heart failure and, in fact, CAP is known to be an exacerbating factor in patients with congestive cardiac failure. ${ }^{28,29}$ COPD is a known frequent co-morbidity in patients admitted to hospital for CAP and respiratory failure. A study of severe CAP in 529 patients in 33 intensive care units in Spain found COPD to be the most frequent co-morbidity. ${ }^{9}$ In our study, COPD was found in $12.8 \%$ of the patients with co-morbidities. Stroke patients may become unconscious and aspirate or have problems with swallowing, and this may predispose them to pneumonia. A high prevalence of HIV has been noted in CAP patients, especially those with pulmonary tuberculosis, suggesting that it is a possible risk factor for developing CAP. ${ }^{30}$ This study showed a low number of CAP patients with HIV infection ( $n=5,10.6 \%)$, because a considerable number of HIV patients seen in the course of the study failed the inclusion criteria because they required anti-tuberculosis treatment (as per the guideline for TB management) instead. The reason is not far-fetched since the duration and drug treatment of tuberculosis is different. Chronic liver disease, chronic kidney disease, and diabetes mellitus were equally observed comorbidities which may predispose patients to CAP by directly or indirectly reducing the immunity. In a study in Brazil of 24 patients with community-acquired staphylococcal pneumonia, 15 of them had comorbidities and $29.15 \%$ of the patients with co-morbidities had diabetes. ${ }^{31}$ The mortality rate among those with co-morbidities in that study was $16.6 \%$.

Similar to findings in other studies, ${ }^{10,11,32}$ this study shows that the CURB-65 rule has high negative and low positive predictive values for 30-day mortality at all cut-off points. It therefore has some ability to predict 30-day mortality in patients with CAP. For identifying high-risk patients, the CURB-65 rule has a low positive predictive value which makes it less useful in guiding decisions for inpatient management. ${ }^{10}$ The sensitivity is high at a low CURB-65 score and specificity is high at a high CURB-65 score. Thus, as the specificity increases the sensitivity decreases and vice versa, which is in agreement with a previous study. ${ }^{10}$ Implications for future research, policy and practice

The findings of this study suggest that severity assessment using CURB-65 should be done in all patients with CAP and more education should be given to doctors and GPs so that the guideline can be used for the optimal management of these patients. A multicentre study is needed in the sub-region to confirm the findings of this study.

\section{Conclusions}

The CURB-65 scoring system has been shown to be a practical tool for assessing the severity and outcome of CAP in Nigeria. It is very useful, particularly in a busy emergency department, because of its simplicity in application and its ability to identify a reasonable proportion of lowrisk patients for potential outpatient care.

\section{Handling editor Mike Thomas Statistical review Gopal Netuveli}

Conflicts of interest The authors declare that they have no conflicts of interest in relation to this article.

Contributorship GCM entered, analysed, and interpreted the data. GCM, CJC, CCO and BJCO drafted and wrote the manuscript. All authors read and approved the final manuscript. GCM is the guarantor of the paper.

Funding None.

Ethical approval Ethical approval was obtained from the ethical committee of the University of Nigeria Teaching Hospital Enugu.

\section{References}

1. Johnson PDR, Irving LB, Turnidge JD. Medical Journal of Australia practice essentials - infectious diseases. 3: Community-acquired pneumonia. Med J Aust 2002;176(7):341-7

2. Marrie TJ, Campbell GD, Walker DH, Low DE. Pneumonias. In: Kasper DL, Braunwald E, Fauci AS, et al. Harrison's principles of internal medicine. 16th ed. New York: McGraw-Hill, 2005. p.1528-9.

3. Sofowara EO, Onadeko BO. Complications and prognostic factors in pneumonia 
among Nigerians. Nigerian Med J 1973;3:144-5.

4. Mokdad AH, Marks JS, Stroup DF, et al. Actual causes of death in the United States. JAMA 2004;291(10):1238-45. http://dx.doi.org/10.1001/jama.291.10.1238

5. Lutfiyya MN, Henlep E, Chang LF. Diagnosis and treatment of CAP. Am Fam Physician 2006;73(3):442-50.

6. Fine MJ, Smith MA, Carson CA, et al. Prognosis and outcome of patients with CAP: a meta-analysis. JAMA 1996;275:134-41. http://dx.doi.org/10.1001/jama.1996.03530260048030

7. Donowitz GR. Are care guidelines useful in CAP? Postgrad Med 2005;118(4):13-17.

8. Fine MJ, Hough $\sqcup$, Medsger AR, et al. The hospital admission decision for patients with CAP: results from the pneumonia patients' outcome Research Team Cohort Study. Arch Intern Med 1997;157(1):36-44 http://dx.doi.org/10.1001/archinte.1997.00440220040006

9. Fine MJ, Auble TE, Yearly DM, et al. A prediction rule to identify low-risk patients with CAP. N Engl J Med 1997;336(4):243-50. http://dx.doi.org/10.1056/NEJM199701233360402

10. Man SY, Lee $N$, Ip M, et al. Prospective comparison of three predictive rules for assessing severity of CAP in Hong Kong. Thorax 2007;62:348-53. http://dx.doi.org/10.1136/thx.2006.069740

11. Lim WS, Van der Eerden MM, Laing R, et al. Defining CAP severity on presentation to hospital: an international derivation and validation study. Thorax 2003;58:377-82. http://dx.doi.org/10.1136/thorax.58.5.377

12. Onyedum CC, Chukwuka JC. Admission profile and management of CAP in Nigeria: 5 year experience in a tertiary institution. Respir Med 2011;105:298-302 http://dx.doi.org/10.1016/j.rmed.2010.11.003

13. Chalmers JD, Singanayagam A, Hill AT. Systolic blood pressure is superior to other haemodynamic predictors of outcome in CAP. Thorax 2008;63:698-702. http://dx.doi.org/10.1136/thx.2008.095562

14. Paganin F, Lilienthal F, Bourdin A, et al. Severe CAP: assessment of microbial aetiology as mortality factor. Eur Respir J 2004;24:779-85. http://dx.doi.org/10.1183/09031936.04.00119503

15. Restrepo MI, Mortensen EM, Pugh JA, Anzueto A. COPD is associated with increased mortality in patients with CAP. Eur Respir J 2006;28(2):346-51. http://dx.doi.org/10.1183/09031936.06.00131905

16. British Thoracic Society Standard of Care Committee. BTS guidelines for management of CAP in adults. Thorax 2001;56(Suppl 4):iv151-64.

17. Cunha BA. Severe community acquired pneumonia. Crit Care Clinic 1998;14:10518. http://dx.doi.org/10.1016/50749-0704(05)70384-5
18. Egbagbe EE, Mordi RM. Aetiology of respiratory tract infections in Benin City. J Med Biomed Res 2006:5(2):22-7.

19. Schaberg T, Giadroni-Grassi G. An analysis of decisions by European general practitioners to admit hospital patients with lower resp. tract infections. The European Study of CAP (ESOCAP) of the European Respiratory Society. Thorax 1996;51:1017-22. http://dx.doi.org/10.1136/thx.51.10.1017

20. Capelastegui A, Espana PP, Quintana JM, et al. Validation of a prospective rule for the management of CAP. Eur Respir J 2006;27:151-7. http://dx.doi.org/10.1183/09031936.06.00062505

21. Ewig S, Ruis M, Mensa J, et al. Severe CAP: assessment of severity criteria. Am J Respir Crit Care Med 1998;158:1102-08.

22. Ewig S, de Raux A, Bauer T, et al. Validation of predictive rules and indices of severity for CAP. Thorax 2004;59:421-7. http://dx.doi.org/10.1136/thx.2003.008110

23. British Thoracic Society Committee and the Public Health Laboratory Service. The aetiology, management and outcome of severe CAP on the ICU. Respir Med 1992;86:7-13. http://dx.doi.org/10.1016/50954-6111(06)80141-1

24. Leeper KV, Torres A. CAP in the intensive care unit. Clin Chest Med 1995;16:15571.

25. Kaplan V, Angus DC, Griffin MF, et al. Hospitalized CAP in the elderly. Am J Respir Crit Care Med 2002;165:766-72.

26. Ochoa-Gonder O, Vila-Corcoles A, Diego C, et al. The burden of CAP in the elderly: the Spanish Evan-65 study. http://www.biomedcentral.com/1471- 2458/8/222.

27. Menendez R, Calvacanti M, Reyes $\mathrm{S}$, et al. Markers of treatment failure in hospitalized CAP. Thorax 2008;63:447-52. http://dx.doi.org/10.1136/thx.2007.086785

28. Bonan JT, Cunha B A. Staphylococcus aureus as cause of CAP in patients with diabetes mellitus. Infect Dis Clin Pract 1999:8:319-21. http://dx.doi.org/10.1097/00019048-199909000-00006

29. Thompson WW, Shay DK, Weintraub E, et al. Mortality associated with influenza and respiratory syncytial virus in the United States. JAMA 2003;289:53-9. http://dx.doi.org/10.1001/jama.289.2.179

30. Fiberesima FPD, Onwuchekwa AC. The prevalence of HIV and TB in acute CAP. Afr J Respir Med 2007;3(1):23-6.

31. Alves dos Santos JW, Nascimento DZ, Guerra VA, et al. Community-acquired staphylococcal pneumonia. J Bras Pneumol 2008;34(9):683-9.

32. Aujesky D, Auble TE, Yealy DM, et al. Prospective comparison of three validated prediction rules for prognosis in CAP. Am J Med 2005;118:384-92. http://dx.doi.org/10.1016/j.amjmed.2005.01.006

Available online at http://www.thepcrj.org 